\title{
Perspektiewe uit die Psalms wat lig werp op die wese van die geloofsgemeenskap
}

\author{
L C Bezuidenhout \\ Universiteit van Pretoria
}

\begin{abstract}
Perspectives from the Psalms which illuminate the essence of the community of faith

The Psalms functioned in contexts which were quite different from that of the modern church, yet they can contribute to a better understanding of the essence of the community of faith. The spirit of a community is revealed in its art more than in its laws. The Psalms constitute the aesthetic residue of the ancient community of faith. Although they do not entail definite laws or regulations concerning the community of faith, they bear witness to the spirituality of the ancient community of faith. In the Psalms certain values can be discerned which are applicable to the modern church.
\end{abstract}

\section{INLEIDING}

1.1 Die relevansie van die Ou Testament vir die bestudering van die kerkbegrip Alhoewel die kerk 'n Nuwe-Testamentiese konsep is, lê die wortels van hierdie konsep in die Ou-Testamentiese begrip van die volk van God. Wanneer daar in 1 Petrus 2:9 verwys word na die wese van die Christelike gemeente, word Eksodus 19:5vv aangehaal as model (vgl Schreiner 1987:8). In die Ou Testament lees ons van die volk van God; daar kan egter na die kerk verwys word as die volk van God in Christus (vgl Breuning 1987:15). Die twee konsepte is nie identies nie, maar daar is beslis raakpunte. Die konsep 'koninkryk van God' kan ook dien as 'n oorbruggingskonsep tussen Ou-Testamentiese gegewens en die Nuwe-Testamentiese kerkbegrip (vgl Lohfink 1987: 33). Hierdie raakpunte maak dit sinvol om die wese van die geloofsgemeenskap van die Ou Testament te bestudeer wanneer daar gevra word na die wese van die kerk. Dit moet egter opgemerk word dat die onmiddelike voorstadia van die Nuwe-Testamentiese gemeente as groepvorming eerder in die vroeë Jodedom te vind is en nie in die $\mathrm{Ou}$ Testament nie (vgl Stendebach 1984:211-224). 


\subsection{Die relevansie van die Psalms vir die bestudering van die geloofsgemeenskap}

Die wese van 'n gemeenskap is meer in sy kuns te vind as in sy reëls. In die Ou Testament kry ' $n$ mens heelwat riglyne vir die funksionering van die geloofsgemeenskap. Tog kan ' $n$ besondere aspek van 'n gemeenskap geken word uit sy liedere. In die liedere vind bewuste en onbewuste waardes neerslag. Een aspek van 'n geloofsgemeenskap word belig deur die wette en reëls vir die gemeenskap. Tog is hierdie aspek sekondêr. Wette konstitueer nie die gemeenskap nie - dit is die sekondêre beskrywing en verskansing van fasette van die gemeenskap wat reeds bestaan. 'n Geloofsgemeenskap kom tot stand deur 'n innerlike dinamika wat eerder kenmerke van spontaniteit vertoon as van legalisme. Die Psalms is by uitstek 'n artistieke beskrywing van die innerlike wese van die geloofsgemeenskap. James Limburg (1992:522) beskryf die Psalms as 'a collection of literature of prayer, praise and meditation'. Dit is belangrik vir sowel die openbare as persoonlike geloofsbelewing van die geloofsgemeenskap.

Die belangrikheid van die Psalms vir bepaalde geloofsgemeenskappe kan afgelei word van die feit dat daar meer kopieë van die Psalms was as van ander boeke in Qumran sowel as onder manuskripte van die Septuagint (Limburg 1992:523).

\subsection{Aspekte van die Psalms: Geykte vorme}

In die Psalms kom geykte vorme voor wat dit moontlik maak om die Psalms in kategorieë in te deel. Die volgende vorme word onderskei: klaagpsalms of -gebede, himnes of lofliedere, dankliedere, koningspsalms, Sionspsalms, wysheid- en Torapsalms (vgl Limburg 1992:531-534). Kraus (1978:66-68) voeg hierby nog 'n kategorie, naamlik feespsalms en liturgieë. Die meeste van hierdie vorme het elkeen 'n bepaalde Sitz-im-Leben in die kultus gehad. In hierdie verband kan die bekende werk van Mowinckel (1967) geraadpleeg word. Alhoewel die studie van die kultiese gebruike van die Psalms uiters belangrik is, lewer dit nie 'n noemenswaardige bydrae tot die verstaan van die moderne kerkbegrip nie. Die verskillende vorme verteenwoordig egter ook behoeftes of waardes wat daar in die geloofsgemeenskap van ouds bestaan het, behoeftes en waardes wat vandag steeds relevant is vir die kerk.

Bestudering van die klaagpsalms en himnes laat ' $n$ mens besef dat hierdie twee vorme nie tot hulle reg kom in die moderne geloofsgemeenskap nie, terwyl dit tog 'n integrale deel behoort te vorm van die geloofsbelewing. Miskien het ' $n$ bepaalde interpretasie van die Nuwe Testament daartoe bygedra dat klaagliedere ongewild geraak het in die Christelike kerk. Tog is daar meriete in die eerlikheid en 'onmiddellikheid' van die klaagpsalms. Dit is nodig vir die gelowige om eerlik met God in gesprek te tree oor sy diepste gewaarwordinge, al beteken dit dat teleurstelling in God self uitgespreek word (vgl Ps 22). Kommunikasie met God behoort nie kunsmatig opgesmuk te wees 
nie - egtheid is belangriker as skyn-vroomheid. Die klaagpsalms gee aan die lydende gelowige die taal waarin ontnugtering uitdruk kan word, terwyl hierdie klag en bede tot God juis in die geloof gerig word. Die gelowige kan dit waag om eerlik te wees en steeds sy/haar verhouding met God koester.

Die loflied het by uitstek tuisgehoort in die samekoms van die geloofsgemeenskap, soos onder ander blyk uit die meervoudsvorm van die uitroep 'Halleluja'. Telkens wanneer die gelowige gered word uit nood, lei dit tot openbare lofsang in die byeenkoms van die geloofsgemeenskap. Ook hierdie aspek kom nie tot sy reg in die moderne geloofsgemeenskap nie. Die lid se deelname aan die byeenkoms van die kerk is grotendeels passief en word nie bewustelik in verband gebring met persoonlike ervarings nie.

Die Psalms het ontwikkel as die hofliedereboek van God as koning (Lohfink 1987: 73). Die geloofsgemeenskap het dit benut om die heerskappy van God te besing, vergelyk Psalms 93-99. Let op hoe teokrasie funksioneer as sleutelbegrip om die geskiedenis van Genesis tot 2 Konings te interpreteer in Psalm 99 (vgl Lohfink 1987:74). Aan die einde van die Psalmboek word daar doelbewus liedere geplaas om die koningskap van God te besing: Psalm 145, 146 en 149. In Psalm 149 word pertinent gesê dat God in die vergadering (קָזָ) as koning besing word. Die motief 'God as herder' word soms verbind met die motief 'God as koning' (vgl Ps 95). Hierdie lofliedere skenk geborgenheid aan die gelowige as burger van die koninkryk van God, as skaap van die kudde van God.

\subsection{Aspekte van die Psalms: Die stilering}

Die vyande in die Psalms is nie 'n spesifieke groep uit 'n spesifieke plek en tyd nie, hulle is enigeen wat vyande van die sangers van die Psalms is (Miller 1983:34). Op dieselfde manier is die aard van die nood en die aard van die verlossing soos dit in die Psalms uitgebeeld word, deel van die stilering van 'n Psalm. Dit word egter deur die sanger geinterpreteer volgens elkeen se omstandighede.

Die stilering van die Psalms het te doen met konvensie. In geloofsbelewing is daar 'n behoefte aan geykte vorme. Binne 'n bepaalde geloofsgemeenskap bied geykte vorme geborgenheid. Vir die moderne mens mag hierdie geykte vorme vreemd voorkom. Om dié rede is daar 'n aandrang om die Psalms só te vertaal dat die moderne mens hom/haar met die beelde kan assosieer. By die omdigting van die Psalms met die oog op die gebruik in die erediens word daar debat gevoer oor die vraag of die oorspronklike idioom nog behou moet word. Dit is egter nie nodig om dit te verander nie. Deur die oorspronklike idioom te behou, beleef die moderne mens solidariteit met die geloofsgemeenskap van ouds. Geykte vorme bied kommunikasie met die geloofsgemeenskap oor die grense van tyd en ruimte. Hierdie kommunikasie is kosbaar en behoort ook in die moderne kerk behou te word. 
Net soos die vorm van die Psalms oorspronklik nie gedui het op konkrete persone of omstandighede nie, so behoort dit ook vir die moderne mens die geleentheid te bied om dit toe te pas op die omstandighede eie aan die bepaalde persoon.

Die stilering van die Psalms lê die klem op gemeenskaplikheid. Tog getuig die Psalms van uniekheid en indiwidualiteit. Hierdie twee eienskappe, gemeenskaplikheid en indiwidualiteit is sleutelbegrippe in die geloofsgemeenskap.

\subsection{Aspekte van die Psalms: Persoonlike ervaring}

Alhoewel die Psalms gegiet is in geykte vorme, is daar telkens by die Psalms tekens van ' $n$ indiwidu se intieıne geloofservaring. Hierdie eienskap maak elke Psalm uniek. Die ervarings wissel van diepste nood: 'My God, my God, waarom het U my verlaat?' (Ps 22:2); tot belewing van verlossing: 'Want U laat my lamp skyn, die Here my God laat my duisternis opklaar' (Ps 18:29); van skuldbesef: '... in ongeregtigheid is ek gebore, en in sonde het my moeder met my swanger geraak' (Ps 51:7); tot ervaring van skuldvergifnis: 'Ek het gesê: Ek wil aan die Here my oortredinge bely; en U het die ongeregtigheid van my sonde vergewe' (Ps 32:5).

Die Psalms verwoord basiese lewenservarings van gelowiges. Brueggemann (1993: 29-41) sien die Psalms as 'n dramatiese stryd wat strek oor gehoorsaamheid (Ps 1), ontnugtering (Ps 73) en lof (Ps 150). Hy gebruik Ricoeur (kyk Brueggemann 1984) se kategorieë: oriëntasie, disoriëntasie en reoriëntasie as basis van waaruit hy die Psalms interpreteer.

Dit is waarskynlik hierdie persoonlike belewenisse wat die Psalms so gewild gemaak het by die geloofsgemeenskap van die verlede en ook van die hede. Daar is persoonlike en openbare fasette van die geloofsgemeenskap. Hierdie fasette hoef nie van mekaar geskei te word nie. Wanneer die indiwidu verlossing beleef, loop dit uit op 'n loflied in die byeenkoms van die geloofsgemeenskap. Gesamentlike beoefening van godsdiens hef nie indiwidualiteit op nie. Dit behoort gesien te word as kollektiewe vormgewing aan indiwiduele geloofsbelewenisse.

\subsection{Aspekte van die Psalms: Die skielike swaai in modaliteit}

Die skielike swaai in modaliteit van klag as gevolg van lyding, na dank as gevolg van verlossing, is moeilik verklaarbaar. Daar is 'n standpunt dat daar op daardie oomblik 'n heilsorakel ontvang is (vgl Begrich 1934:81; Gunkel-Begrich 1933:245; Westermann 1981:65; Bellinger 1984:81). Daar is ook die moontlikheid van die voorwaardelike gelofte. Die biddende persoon gee 'n aanduiding van hoe sy lof sal wees, indien sy gebed verhoor word as 'n motivering vir God om sy gebed wel te verhoor (vgl Cartledge 1987:83). Hierdie verklarings is geldig, maar daar is ook ander moontlikhede. 
Dit is moontlik dat ' $n$ vergeesteliking plaasgevind het ten opsigte van die heilsorakel. Gedurende die klaaglied ervaar die persoon 'n ommeswaai in gemoedstoestand en druk dit uit in woorde wat ooreenkom met dank na 'n werklike verlossing (vgl Gunkel-Begrich 1933:245; Soggin 1976:373).

Die erediens as konkrete vergestalting van die moderne geloofsgemeenskap behoort ook gekenmerk te word deur 'n geestelike dinamika waardeur die deelnemer 'n hernuwing van die verhouding met God ervaar en tot 'n meer positiewe lewensuitkyk kom.

\subsection{Aspekte van die Psalms: Die geloofsgemeenskap as volk van God}

Een van die raakpunte tussen Israel in die Ou Testament en die Christelike kerk, is die feit dat beide groepe hulleself sien as die volk van God wat uitverkies is tussen ander groeperinge om vir God 'n heilige volk te wees (vgl Ps 33, 79, 95, 100, 114 en 115; Fuhs 1987:143).

Israel word in die Ou Testament voorgestel as die volk van God. Hierdie tipering dui op sowel 'n staatkundige groepering as 'n geloofsgemeenskap. Daar het 'n verskuiwing plaasgevind van ' $n$ staatkundige groepering tot 'n geloofsgemeenskap (vgl Hossfeld 1987:123). Hierdie verskynsel is veral merkbaar by die Deuteronomis en die Priesterlike geskrif (vgl Hossfeld 1987:125).

In die Psalms word die woord קָָ by uitstek gebruik om te verwys na die geloofsgemeenskap. Die volgende Psalms is voorbeelde:

* Psalm 22:23: 'Ek wil u Naam aan my broers vertel, in die vergadering U prys'

* Psalm 22:26: 'Van U kom my lof in 'n groot vergadering';

* Psalm 35:18: 'Ek sal U loof in 'n groot vergadering';

* Psalm 40:10: 'Ek het 'n blye boodskap van geregtigheid in die groot vergadering verkondig';

* Psalm 40:11: ‘... u goedertierenheid en u trou verberg ek nie vir die groot vergadering nie';

* Psalm 89:6: 'En die hemele loof ... ook u trou in die vergadering van die heiliges';

* Psalm 107:32: 'En laat hulle Hom verhoog in die vergadering van die volk en Hom roem in die kring van die oudstes'; en

* Psalm 149:1: 'Sing ... sy lof in die vergadering van die gunsgenote'.

Alleen in Psalm 26:5 verwys die woord nie na die geloofsgemeenskap nie. In Psalms 22:26, 35:18 en 40:10-11 word die grootte van die gemeenskap met die woord 2 omskryf. Hierby kan Psalm 107:32 gevoeg word wat na die vergadering van die volk verwys. Die vergadering impliseer ' $n$ groot getal mense. Tog is dit die indiwidu wat God wil loof vir 'n besondere weldaad. 
In Psalms 89:6 en 149:1 word die kwaliteit van die vergadering verder gekwalifiseer met die beskrywing: vergadering van die heiliges, vergadering van die gunsgenote.

Soms word die woord לדָ T⿱乛⿻ in 'n chiasme of parallelisme teenoor ander begrippe geplaas: Psalms 22:23; 35:18 en 107:32 word chiasties opgebou. In Psalm 22:23 word 'aan my broers' en 'in die vergadering' teenoor mekaar gestel; in Psalm 35:18 'groot vergadering' en 'groot skare'; in Psalm 107:32 'vergadering van die volk' en 'kring van die oudstes'. Dit wil voorkom asof hierdie teenstellings daarop dui dat die lof van God sowel in die godsdienstige byeenkomste as in die profane byeenkomste verkondig moet word. In Psalm 22:26 staan die uitdrukking 'groot vergadering' teenoor 'die wat Hom vrees'. In hierdie geval kan die twee begrippe as parallelle begrippe gesien word. In Psalm 89:6 word die 'hemele' gestel teenoor 'die vergadering van die heiliges'. In hierdie geval dien die teenoorstelling op algehele lof aan God, tussen die hemelinge sowel as dié op aarde wat aan God gewy is. Dit wil voorkom asof die woord קָָָ aanvanklik op 'n gewone vergadering gedui het. So word dit in die vooreksiliese Psalm 26 gebruik. Later het dit ontwikkel tot 'n tegniese term wat spesifiek op die godsdienstige byeenkoms dui (Hossfeld \& Kindl 1989:1218-1219).

Ander woorde wat in die Psalms gebruik word om na die geloofsgemeenskap te

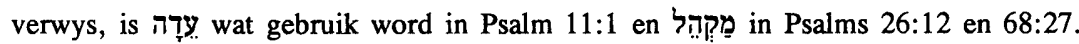

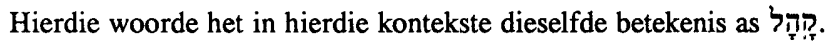

Die gelowiges beleef hulle godsdiens op 'n persoonlike vlak, maar hulle besondere verhouding met God hou verband met hulle lidmaatskap van die geloofsgemeenskap. Die geloofsgemeenskap word die plek waar die enkeling se reaksie op die ingryping van God uitmond as lof aan God.

\subsection{Aspekte van die Psalms: Die tipering van die vrome}

In die Psalms word die vrome getipeer deur te verwys na sy verhouding met God, met ander vromes, teenoor die Tora en teenoor die vyandige magte. In sy proefskrif het Botha (1986:330-350) tot bogenoemde gevolgtrekking gekom ten opsigte van Psalm 119, maar hierdie tipering geld ook vir die ander Psalms. Die geloofsgemeenskap bestaan uit vromes. Wanneer daar vandag gepraat word oor die tipering van die 'kerk', sal dit sinvol wees om, bogenoemde tipering in aanmerking te neem.

\subsection{Aspekte van die Psalms: Die estetiese aspek van geloofsbelewing}

Daar is geloofswaarhede wat nie logies verwoord kan word nie, dit kan net besing word. Bestudering van die Psalm bring erkenning vir die estetiese dimensie as noodsaaklike dimensie van die leefwêreld van die geloofsgemeenskap. Die Psalms is lite- 
rêre kuns van hoogstaande gehalte. In die moderne geloofsgemeenskap word daar klem gelê op die dogmatiese en etiese dimensie, maar die estetiese dimensie word veral in Reformatoriese kringe verwaarloos.

Daar behoort weer 'n kreatiewe tyd aan te breek waarin kunsvorme tot stand kom waardeur die mens uiting kan gee aan die diepste gewaarwordinge wat 'n gelowige ervaar: die enigma van lyding, die onvoorwaardelike vertroue op God en die onuitspreeklike dank en lof aan God.

\section{SLOTOPMERKING}

Daar word vandag baie riglyne gegee vir die ordening van die geloofsgemeenskap of kerk. Tog is die wesenlike van die geloofsgemeenskap nie geleë in die reëls wat dit inhibeer nie, maar in die spontane kreatiwiteit van die geloofsgemeenskap. Wanneer die Psalms, asook die Bybel, bestudeer word met die oog op die beskrywing van die kerkbegrip, behoort dit nie gesien te word as 'n soeke na reëls nie. Daar behoort eerder geput te word uit die rykdom van die geloofsgemeenskap van ouds, sodat dit stimulerend kan inwerk op die moderne geloofsgemeenskap. Dit kan nuwe impetus gee aan verwaarloosde fasette van geloofsbelewing binne die geloofsgemeenskap: spontane, eerlike kommunikasie met God oor die hele spektrum van belewenisse, van die klaaglied tot die loflied.

\section{Literatuurverwysings}

Begrich, J 1934. Das priesterliche Heilsorakel. ZAW 52, 81-92.

Bellinger, W H (jr) 1984. Psalmody and prophecy. Sheffield: JSOT Press. (JSOT Supplement Series 27.)

Botha, P J 1986. Die teologiese funksie van die Torah-woordveld in die driehoeksverhouding Jahweh-vrome-vyand in Psalm 119. DD-proefskrif, Universiteit van Pretoria.

Brueggemann, W 1984. The message of the Psalms: A theological commentary. Minneapolis: Augsburg. (Augsburg Old Testament Studies.)

- 1993. Response to James L Mays, 'The question of context', in McCann, J C (Jr) (ed), The shape and shaping of the Psalter, 29-41. Sheffield: JSOT Press. (JSOT Supplement 159.)

Breuning, W 1987. Wie 'definiert' sich Kirche heute? in Schreiner 1987:11-32.

Cartledge, T W 1987. Conditional vows in the Psalms of lament: A new approach to an old problem, in Hoglund, $\mathrm{K} \mathrm{G}$ et al (eds), The listening heart: Essays in wisdom and the Psalms in honor of Roland E Murphy, 77-94. Sheffield: JSOT Press. (JSOT Supplement Series 58.) 
Fuhs, H F 1987. Heiliges Volk Gottes, in Schreiner 1987:143-167.

Gunkel, H \& Begrich, J 1933. Einleitung in die Psalmen: Die Gattungen der religiosen Lyrik Israels. Göttingen: Vandenhoeck.

Hossfeld, F-L 1987. Volk Gottes als 'Versammlung', in Schreiner (1987:123-142).

Hossfeld, F-L \& Kindl, E-M 1989. s v קָָָ Theologisches Wörterbuch zum Alten Testament, Band VI.

Kraus, H-J 1978. Psalmen. Neukirchen-Vluyn: Neukirchener Verlag. (BKAT.)

Limburg, J 1992. Psalms, book of, in Freedman, D N (ed), The Anchor Bible dictionary, Vol 5, 522-536. New York: Doubleday.

Lohfink, N 1987. Der Begriff des Gottesreichs vom Alten Testament her gesehen, in Schreiner 1987:33-86.

Miller, P D 1983. Trouble and woe: Interpreting the Biblical laments. Interp. 37, 3245.

Mowinckel, S 1967. The Psalms in Israel's worship, translated by D R Ap-Thomas. Oxford: Basil Blackwell.

Schreiner, J 1987. Unterwegs zur Kirche: Alttestamentliche Konzeptionen. Freiburg: Herder.

Soggin, J A 1976. Introduction to the Old Testament. London: SCM. (OTL.)

Stendebach, F J 1984. Versammlung - Gemeinde - Volk Gottes: Alttestamentliche Vorstufen von Kirche? Judaica 40, 211-224.

Westermann, C 1981. Praise and lament in the Psalms. Edenburgh: T \& T Clark. 